\title{
Pediatric Burns at The Rift Valley Provincial General Hospital, Nakuru, Kenya
}

Author: Oduor P.R., MBChB, MMed, Department of Surgery, Rift Valley Provincial General Hospital, Nakuru, Kenya. P.0. Box 1216820100, Nakuru. E-mail: oduorpr@gmail.com

\section{Abstract}

Aim

To determine the etiology and outcome of pediatric burns ( 0 -12 years).

Design

A retrospective study of burn victims hospitalized at the Rift Valley Provincial General Hospital, Nakuru, Kenya from April 2004 to March 2007

Method

Charts of all children hospitalized for burn injury were reviewed for patient demographics, burn etiology, anatomical sites involved, extent of burn and outcome of treatment.

\section{Results}

The mean age was 2.6 years, with a male to female ratio of $1.4: 1.90 .2 \%$ of the burns were due to scalds. The upper limbs and trunk were the most commonly affected. The mortality was $11.9 \%$ with flame burns resulting in a higher mortality than scalds.

Conclusion

The management of burns in the Nakuru region is challenging. The morbidity and associated mortality is high. Prevention of burn injuries should be advocated.

\section{Introduction}

Burns are a leading cause of unintentional injury in the developing world. In Africa, poverty, mass illiteracy, migration to urban areas with development of slum areas and shanty towns contribute to increasing incidence (1). Most hospitalized burn patients worldwide are children under 5 years of age.

The injury, treatment, and rehabilitation process affect children not only physiologically, but psychologically as well (2). Admissions of pediatric burn injuries in the Rift Valley Provincial General Hospital have been on the increase. This review was undertaken to address the scarcity of valid data on the epidemiology of pediatric burns at The Rift Valley Provincial General Hospital and the greater Nakuru region. It analyses the etiology, severity and the relationship between these and patient demographics.

\section{Methodology}

The study was carried out at the Rift Valley Provincial General Hospital over a 3-year period from April 2004 to March 2007. All children admitted in the pediatric surgical/female burn ward were eligible. On average the ward admits 680 patients a year out of which 170 patients $(25.7 \%)$ are due to pediatric burns. The Hospital attracts patients mostly from low socioeconomic status from Nakuru and the surrounding districts. An institutional review board approved the study.

Admission registers and the patients' files from the medical records department were used as sources of information. The information obtained included age, sex, cause of burn injury, total body surface area (TBSA) burned, depth of burn injury, length of time between injury and length of stay in the hospital. The extent of burn was determined by Lund and Browder charts. The relationship between the main outcome (death or discharge) and cause of burn, extent of burn and patient age was also explored. Data was analyzed using the Statistical Package for Social Sciences. The results are expressed as proportions.

\section{Results}

A total of 530 patients between the ages of 0-12 years were reviewed.

\section{Patient demographics}

The age groups most affected were 0.5 to 1.5 years (n $=167,32 \%$ of the cases $)$ and 1.5 to 2.5 years $(n=143$, $30 \%$ of cases) (Fig. 1). The mean age for the patients was 2.6 years. Boys copmrised 59.1 percent of the cases (ratio, 1.4:1) 


\section{Cause of Burns}

Hot liquids accounted for $84 \%$ (445 children) of the burn injuries, followed by flame burns/fire at 9.8\% (52 children), porridge at $4.3 \%(n-23)$ and hot food $(n=10)$ related injuries at $1.9 \%$.

With regard to the hot liquids, $86 \%$ were caused by hot liquids in pots/sufurias, while hot liquids in the cup/ mug, kettle and basin caused 7.2\%, 3.4 and 3.4\% of the burns respectively. Of the flame burns, $68 \%$ were caused by charcoal or firewood while $32 \%$ were as a result of kerosene initiated burns.

\section{Area of Burn and Burn Severity}

Most of the victims sustained burn injuries in multiple areas. Majority of the burns involved the upper limbs (58\%) and the trunk (42\%) (Fig.2).

Majority of the victims sustained burn injuries ranging from $2.2 \%$ to $7.5 \%$ ( 228 cases or $43 \%$ of cases), followed by burn injuries of $7.5 \%$ to $12.5 \%$ (140 cases or $26 \%$ of the cases) (Fig. 3). Generally $88.9 \%$ (471 cases) of the patients sustained under $18 \%$ burns.

Fires caused the most extensive burns compared to the other etiological agents. With regards to patients with fire burns, approximately $28.8 \%$ had more than $19 \%$ burn area compared to $6.7 \%$ for hot liquid burns (table 1)

\section{Outcomes}

Eighty four percent $(\mathrm{n}=445)$ of the burn patients were discharged after hospitalization, 12\% (n 63) of the children died while $4 \%$ of the admitted cases either absconded or were transferred to other medical facilities. There was a relationship between cause of burn and fatality resulting from the burn injuries. Approximately 1 in every 3 patients with flame burns (34\% of flame cases) died. For hot liquid burns, this proportion was 10.6\% (approximately 1 in every 9 hot liquid cases). Food related burns were not fatal (Table 1).

For the relationship between burn extent and fatality, $72.7 \%$ of the patients who sustained more than $19 \%$ burn injuries died compared to $19.9 \%$ and $0.9 \%$ of those with 10 - 19\% burns and less than $10 \%$ burns respectively (Table 2)

Approximately 1 in every 18 victims (5.6\% of cases) above 4 years of age succumbed to their injuries compared to one in every 7 of patients ( $13.5 \%$ of cases) be-

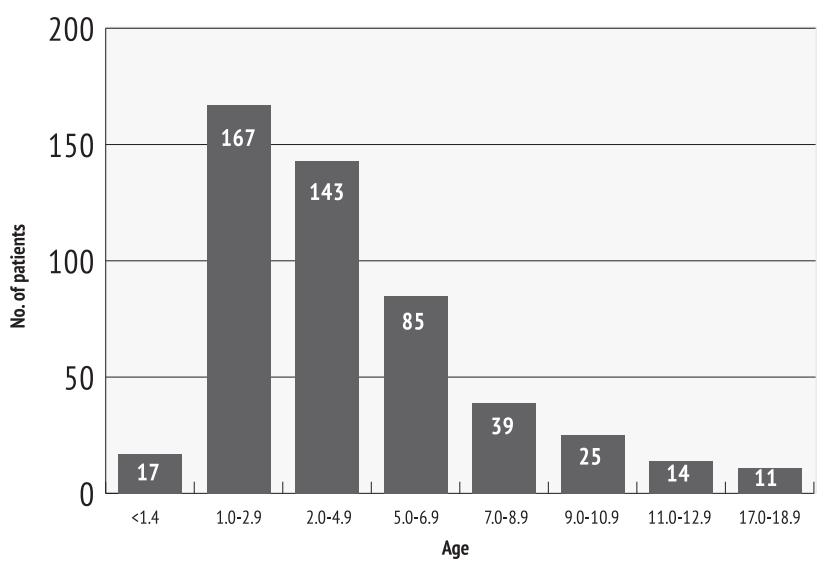

Figure 1: Age distribution of burn children at Nakuru PGH

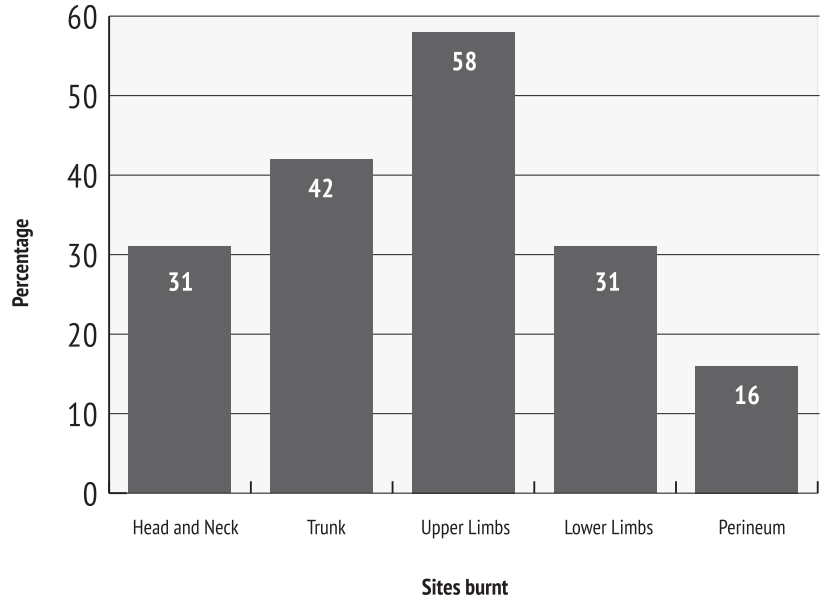

Figure 2 (sites burnt)

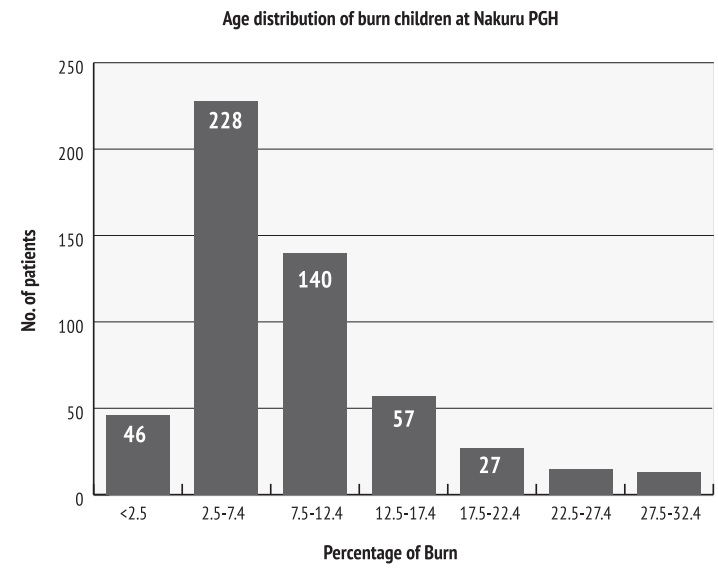

Figure 3 Extent of pediatric burn at the RVPGH 


\section{Epidemiology of pediatric burns at The Rift Valley Provincial General Hospital, Nakuru, Kenya}

\begin{tabular}{|c|c|c|c|c|}
\hline \multirow[t]{2}{*}{ Cause of Burn } & & \multirow{2}{*}{$\begin{array}{l}\text { Fatality } \\
\text { Death }\end{array}$} & \multicolumn{2}{|l|}{ Total } \\
\hline & & & Discharge & \\
\hline \multirow[t]{3}{*}{ Porridge } & Frequency & 1 & 21 & 22 \\
\hline & \% Within Porridge & $4.5 \%$ & $95.5 \%$ & $100.0 \%$ \\
\hline & $\%$ of total & $0.2 \%$ & $4.1 \%$ & $4.3 \%$ \\
\hline \multirow[t]{3}{*}{ Hot Liquid } & Frequency & 45 & 381 & 426 \\
\hline & \% Within Hot Liquid & $10.6 \%$ & $89.4 \%$ & $100.0 \%$ \\
\hline & $\%$ of total & $8.9 \%$ & $75.0 \%$ & $83.9 \%$ \\
\hline \multirow[t]{3}{*}{ Fire } & Frequency & 17 & 33 & 50 \\
\hline & \% Within Fire & $34.0 \%$ & $66.0 \%$ & $100.0 \%$ \\
\hline & $\%$ of total & $3.3 \%$ & $6.5 \%$ & $9.8 \%$ \\
\hline \multirow[t]{3}{*}{ Food } & Frequency & 0 & 10 & 10 \\
\hline & \% Within Food & $0.0 \%$ & $100.0 \%$ & $100.0 \%$ \\
\hline & $\%$ of total & $0.0 \%$ & $2.0 \%$ & $2.0 \%$ \\
\hline \multirow[t]{2}{*}{ Total } & Frequency & 63 & 445 & 508 \\
\hline & $\%$ of total & $12.4 \%$ & $87.6 \%$ & $100.0 \%$ \\
\hline
\end{tabular}

Table 1: Relationship between cause of burn and mortality

\begin{tabular}{lllll} 
Percentage Burn & & Fatality & \multicolumn{2}{l}{ Total } \\
\hline Less than 10\% & Frequency & 3 & \multicolumn{2}{l}{ Discharged } \\
\hline & \% Within 10\% burns & $0.9 \%$ & 320 & 323 \\
\hline & \% of total & $0.6 \%$ & $69.1 \%$ & $100.0 \%$ \\
\hline $10 \%$ to 19\% & Frequency & 28 & 113 & 141 \\
\hline & \% Within 10-19\% burns & $19.9 \%$ & $80.1 \%$ & $100.0 \%$ \\
\hline More than 19\% & \% of total & $5.5 \%$ & $22.2 \%$ & $27.8 \%$ \\
\hline & Frequency & 32 & 12 & 44 \\
\hline \% Within $>19 \%$ burns & $72.7 \%$ & $27.3 \%$ & $100.0 \%$ \\
\hline Total & \% of total & $6.3 \%$ & $2.4 \%$ & $8.7 \%$ \\
\hline & Frequency & 63 & 445 & 508 \\
\hline
\end{tabular}

Table 2: Relationship between extent of burn and outcome

countries, Brazil, Greece, Bangladesh and India (3-9). The latter studies have however tended to depict a gender ratio much higher in favor of boys, $1.6: 1$ to $1.75: 1(4-9)$. Safety of the home environment is an issue of concern as is true elsewhere $(4,10-11)$. The low socioeconomic status of the patients we see contributes to this, since the home environment does not provide for the safety of the child. In many instances, the space inside the dwelling is used for both cooking and sleeping (11). Since most are not able to afford house helps, they perform the household chores with the children around them such that any lapse in concentration can allow the child to come into contact with a burning agent. Most are therefore preventable.

Scalds caused most burns (90\%) and most $(86 \%)$ of the burns arising from cooking pots. This strengthens the fact that the safety of the cooking area is a major problem. In low and middle income countries scalds have been found to cause most burns in the younger children (12-14), with flame burns being more significant in the older children who tend to venture more outdoors.

Most of the burns affected multiple sites though the upper limbs and trunk were the most affected. Previous studies have also reported the upper extremity as the part most frequently affected (14-16). Younger children or toddlers have a tendency to reach for objects high up hence, spillage occurs onto the upper limb then the trunk. Food preparation using open cast iron pots for cooking food and boiling water constitute a major hazard for small children and toddlers as they often play around the cooking area (11).

The fatality rate of $12 \%$ is higher as compared to studies in other parts of the world where

low five years of age.

\section{Discussion}

The present study shows that pediatric burns predominantly affect boys aged 0.5 to 2.5 years of age and within their home environments. These findings corroborate recent epidemiological studies from several African reported rates ranged from $1.3 \%$ to $6.4 \%(9,17)$. In low and middle income countries, however, mortality of 9.9\% for burns reaching $21.3 \%$ have been reported (18). Flame burns had a higher mortality, 34\%, compared to scalds, $10.6 \%$. This could be because the fires caused more extensive and deeper burns. Open fires are also more likely to be associated with inhalation injuries. In- 
creased burn size leads to increased risk of mortality among children (9). A study in Kuwait found that among non survivors flame burns caused 9 out of 11 fatalities (19). Burn extent is an indication of severity of burn and in our study $72.7 \%$ of patients who had an extent of more than $19 \%$ succumbed to their injuries. This may be explained by the fact that about $87 \%$ of our patients were under the age of 5 years. Egar and Clark reported that even small burns could cause death in children (20). Hemmet et al in their study in Tabriz, Iran noted that non survivors with small burns acted as an important reminder that children can die from small burns (9). Reasons cited for the higher burn mortality rate in children include an immature immune system and increased fluid requirements, which place children at a higher risk for sepsis and hypovolaemic shock after burn injury $(21,22)$. This emphasizes the fact that children with extensive burns require very close monitoring and would benefit from admission into a dedicated pediatric burn ward. This is unlike what we have in our set up.

Burns in children have a profound effect both on the family and the child. To the family, the mother has to abandon her responsibilities to care for the child in hospital. She may be forced to leave the other children in the care of the husband who is normally the bread winner and has to go to work. For the child the impact is not only physical but psychological as well. The management of pediatric burns is therefore a big challenge in Africa. This means that our aim should be burn prevention.

We recommend further studies to determine the knowledge, attitude, practice of parents and caretakers with regards to burn injury as a possible entry point for preventive measures. Studies on safer communities for children including the cooking environment may start to address the problem.

The challenge is not in the successful treatment of a severe burn wound, but rather in the successful prevention of thermal injuries (23). Pediatric burns must therefore

\begin{tabular}{|c|c|c|c|c|}
\hline \multirow[t]{2}{*}{ Age } & & Fatality & \multicolumn{2}{|l|}{ Total } \\
\hline & & Death & \multicolumn{2}{|c|}{ Discharged } \\
\hline \multirow[t]{3}{*}{ Under five year } & Frequency & 59 & 377 & 436 \\
\hline & $\%$ Within patients under 5 & $13.5 \%$ & $86.5 \%$ & $100.0 \%$ \\
\hline & $\%$ of total & $11.6 \%$ & $74.2 \%$ & $85.8 \%$ \\
\hline \multirow[t]{3}{*}{5 to 12 years } & Frequency & 4 & 68 & 72 \\
\hline & $\%$ Within patients over 4 & $5.6 \%$ & $94.4 \%$ & $100.0 \%$ \\
\hline & $\%$ of total & $0.8 \%$ & $13.4 \%$ & $14.2 \%$ \\
\hline \multirow[t]{2}{*}{ Total } & Frequency & 63 & 445 & 508 \\
\hline & $\%$ of total & $12.4 \%$ & $87.6 \%$ & $100.0 \%$ \\
\hline
\end{tabular}

Table 4: Relationship between patient age and mortality

\begin{tabular}{llllll} 
Cause of Burn & \multicolumn{2}{l}{ Percentage burn } & \multicolumn{2}{l}{ Total } \\
\hline & & Less & $10 \%$ & \multicolumn{2}{l}{ More } \\
\hline Porridge & Frequency & than $10 \%$ & to 19\% & than 19\% \\
\hline & \% within Porridge burns & $73.9 \%$ & $26.1 \%$ & $.0 \%$ & $100.0 \%$ \\
\hline Hot Liquid & Frequency & $3.2 \%$ & $1.1 \%$ & $.0 \%$ & $4.3 \%$ \\
\hline & \% within hot liquid burns & $64.7 \%$ & $28.5 \%$ & $6.7 \%$ & $100.0 \%$ \\
\hline Fire & \% of Total & $54.3 \%$ & $24.0 \%$ & $5.7 \%$ & $84.0 \%$ \\
\hline & Frequency & 23 & 14 & 15 & 52 \\
\hline Food & \% within fire burns & $44.2 \%$ & $26.9 \%$ & $28.8 \%$ & $100.0 \%$ \\
\hline & \% of Total & $4.3 \%$ & $2.6 \%$ & $2.8 \%$ & $9.8 \%$ \\
\hline & Frequency & 9 & 1 & 0 & 10 \\
\hline Total & \% within food burns & $90.0 \%$ & $10.0 \%$ & $.0 \%$ & $100.0 \%$ \\
\hline & \% of Total & $1.7 \%$ & $.2 \%$ & $.0 \%$ & $1.9 \%$ \\
\hline & Frequency & 337 & 148 & 45 & 530 \\
\hline & \% of Total & $63.6 \%$ & $27.9 \%$ & $8.5 \%$ & $100.0 \%$ \\
\hline
\end{tabular}

Table 1: Relationship between cause of burn and severity (extent of burn)

be considered a public health problem in Kenya and other African countries as has happened in Asia.

\section{References}

1. Oluwasanmi JO. Burns in Western Nigeria. Br J Plast Surg $1996 ; 22(3): 216-23$

2. Meyer Jr W, Blakeney P, Russel W, et al. Psychological problems reported by young adults who were burned as children. J. Burn Care Rehabil 2004, 25(1) 98-106 


\section{Epidemiology of pediatric burns at The Rift Valley Provincial General Hospital, Nakuru, Kenya}

\section{Oduor P.R.}

3. Niekern AV, Rode H, Laflamme L. Incidence and pattern of childhood burn injuries in the Western Cape, South Africa. Burns 2004;30 : 341-7

4. Rossi LA, Braga ECF, Barruffini RCB, et al. Childhood burn injuries: Circumstances of occurrence and their prevention in Ribeirao Preto, Brazil. Burns 1998; 24 : 416-9

5. Shirani K, Pruit B, Mason A. The influence of inhalation injury and pneumonia on burn mortality. Ann Surg 1987; 205: 82

6. Chattergee BF, Barancik JI, Fratiense RB et al. North Eastern Ohio trauma study V Burn Injury. J Trauma 1986; 26: 844

7. El- Badawy A, Mabrouk AR. Epidemiology of pediatric burns in the burn unit of Ain Shams University in Cairo, Egypt. Burns 1998; 24: 728-32

8. Lari ARA, Bang RL, Ebrahim MJKM, et al. An analysis of childhood burns in Kuwait. Burns 1992; 18:224

9. Hemet M, Naser Samnia. Etiology and outcome of pediatric buns in Tabriz, Iran. Burns 2005; 31: 721-25

10. Forjuoh SN. Burns in low- and middle-income countries: A review of available literature on descriptive epidemiology, risk factors, treatment, and prevention. Burns 2006; 32: 52931

11. Onuba $\mathrm{O}$, Udoidoik E. The problem and prevention of burns in developing countries. Burns 1987; 3(5): 382-5

12. Mukerji G, Chamamia S, Patidar GP, et al. Epidemiology of pediatric burns in Indore, India. Burns 2001; 27: 33-8
13. Bang RL, Ebrahim MK, Shauma PN. Scalds among children in Kuwait. Burns 199; 18(3):224-7

14. Vilasco B, Bondurand A. Burns in Abidjan, Cote D'Ivoire. Burns 1995;21:291-6

15. Forjuoh SN, Guyer B, Smith GS. Childhood burns in Ghana: epidemiological characteristics and home based treatment. Burns 1995; 21:24-8

16. Cheng JCY, Leung KS, Lam ZI, et al. An analysis of 1704 burn injuries in Hong Kong children. Burns 1990; 16:182-4

17. Mercier C, Blond MH. Epidemiological survey of childhood burn injuries in France. Burns 1996; 22(1):29-34

18. Adamo C, Esposito G, Lissia M, et al. Epidemiological data on burn injuries in Angola: a retrospective study of 7230 patients. Burns 1995; 21: 536-8

19. Sharma PN, Bang RL, Al-Fadhli AN et al. Pediatric burns in Kuwait. Incidence, causes, and mortality. Burns 2006;32: 104-111

20. Egan WC, Clark WR. The toxic shock syndrome in a burned victim. Burns 1988;14: 135-8

21. McLoughlin E, McGuire A. The causes, cost, and prevention of childhood burn injuries. Am J Dis Child 1990; 144: 67283

22. Meorel SW, Saffle JR, Sullivan JJ et al. Fluid resuscitation in the thermally injured children. Am J. Surg 1986; 152: 664-9.

23. Albertyn R, Bickler SW. Rode H. Pediatric burn injuries in Sub-Saharan Africa-an overview. Burns 2006; 32(5):605-12. 